\title{
Stability Ball on Glycaemic Control in Type 2 Diabetes Mellitus
}

\author{
Subramanian SS1 and Venkatesan P2.
}

\begin{abstract}
Diabetes mellitus, one of the top non-communicable diseases globally, particularly among Indian population, has huge impact on the health of the individual, nation, as well as economical percussion. Lifestyle modifications including dietary modifications, improved physical activities remain key components in the therapeutic and preventive means of Type 2 diabetes mellitus. The effectiveness of Exercises using stability ball in the glycaemic control and weight reduction among type 2 diabetes mellitus are dealt with in this study.
\end{abstract}

Key Words: Type 2 diabetes, Stability Ball

NOTE: Stability ball is also called physio ball, swiss ball / gym ball, which is an air inflated ball of $550 \mathrm{~mm}$ diameter which is widely used as a rehabilitation tool in physiotherapy.

\section{Introduction:}

Diabetes poses a major health problem globally and is one of the top 5 leading causes of death (King, Albert et al 1998). By the year 2025, the worlds 300 million adults with diabetes will be in developing countries, almost 1/3rd in India and China alone (Fall et al 2001). Asian Indian phenotype is considered to be one of the major factors contributing to the increased predilection towards diabetes (Joshi R 2003). Asian Indians have a greater degree of central obesity (Ramachandran, Snehalatha 1997) and have total abdominal and visceral fat for any given Body mass index and for any given body fat have increased insulin resistance (Raji, Seely et al 2001). Most disturbing trend is the shift in the age of onset of diabetes to a younger age in recent years, which could have more percussions on health and economy of individual hence on the nation, (Mohan, Deepa et al 2006) with changes in dietry pattern (Sterlin, Baur et al 1996) and decreased physical activities (Mohan, Shanthi rani et al 2003). Higher prevalence of diabetes in the urban population (Ramachandran, Snehalatha et al 2002) were well recorded.

Appropriate life style interventions including changes in dietry pattern, regular exercises would greatly help in preventing or postponing the onset of diabetes and thus reducing the burden on society and nation (Knavler, Barrett et al 2002). Chennai city has a known prevalence of Type 2 diabetes at 12\% (Ramachandran, Snehalatha et al 2001). Type 2 diabetes accounts for $90 \%$ of all diabetic cases (Wild, Foglic et al 2004).

The American diabetes association (ADA) recommends that individuals with Type 2 diabetes should perform atleast 90minutes of vigorous aerobic exercises per week or should perform atleast 150 minutes of moderate aerobic exercises per week (ADA 2002). Vibration exercises are an effective, lowtime consuming tool to enhance glycaemic control in Type 2 diabetic patients (Klans Banm et al 2007). Glycaemic control improves with resistance training (University of calgary, Ottowa 2007).

The purpose of this study was to evaluate the effects of moderate intensity exercises using stability ball on glycaemic control among male Type 2 diabetic patients.

\section{Materials And Methods:}

Participants in this study were recruited by special diabetic camp organised during July 2010. This study was conducted at Sree Balaji College of Physiotherapy, Chennai-100. 60 subjects, diagnosed with Type 2 diabetes mellitus patients on due medication between the age group of 30-60 years were randomly assigned to 12 weeks supervised control group $(n=30)$ or moderate intensity resistance exercises using stability ball $(n=30)$.

All the subjects glycelated haemoglobin and body mass index (BMI) were recorded before training (i.e., 0 week) and after 12 weeks of training.

Inclusion criteria were Non insulin dependent, diagnoses with Type 2 diabetes, male between 30-60 years.

Participants of the camp were evaluated by medical and physical means to exclude individuals with subjective or objective evidence of uncontrolled diabetes mellitus, severe musculoskeletal impairment, those with uncontrolled hypertension and who underwent coronary artery bypass surgery.

Written informed consent to participate in the study were obtained from all the subjects.

\section{Outcome Measure:}

All the subjects were tested on two occasions by using same protocols. Venous blood samples of all the participants were taken, measured and analysed for Glycelated hemoglobin before the intervention i.e., 0 week 
and after the intervention (12th week)

\section{Anthropometric Measures:}

Height in centimeters and weight in kilogram of all the subjects were measured and body mass index was calculated and recorded prior to starting this study after completion of 12 weeks of intervention. Height and weight was measured and BMI was calculated for all the subjects, recorded and analysed using due statistical means.

\section{Intervention:}

Subjects alloted to this group have performed systemic supervised resistance training as per the guidelines of ADA(American Diabetic Association) and ACSM (American College of Sports Medicine). Subjects have performed three sets of 10 exercises and 5 repetitions of each exercise per session. Thrice a week they have exercised for a period of 12 weeks. The exercises performed using stability ball involved of using major muscle groups such as Lumbar spine extensors, Abdominals, Gluteus Maximus, Quadriceps Femoris, Hamstrings and Gastrocnemius. All the physical activity were of the nature of closed kinematic chain exercises and using isometric co-contraction of many lower extremity muscles. Also body weight of the subjects providing resistance to each activity, hence peak torque produced with every physical activity using the stability ball.

Progression in intensity was designed in such a way that upto four weeks no holding of each physical activity, Five second hold of each activity during the period from 8-12 weeks were practiced.

\section{Control Group:} activities.

Subjects allotted in this group underwent no specific training other than their daily routine physical

All the subjects in control group and stability ball exercise groups continued their prescribed medication and daily routine activities.

\section{Results} occured.

All the participants completed the training period of 12 weeks. No injuries or hypoglycaemic incidents

\section{Body Mass Index(BMI);}

Subjects in stability ball exercise group where there was a decrease by 1.6 in the mean value which is significant, where as mean value among control group subjects has increased by 0.5 as shown below in graph 1

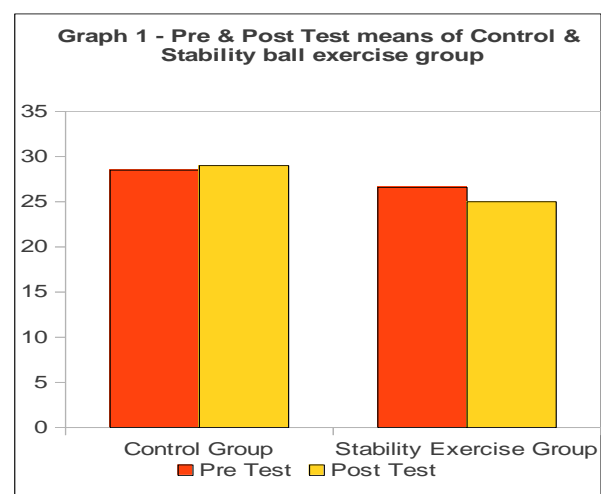

Initial measurements and post training changes in Body Mass Index of both control and stability ball exercises were analysed using paired 't' test. Statistical tests were performed using SPSS software.

Table 1: Results of paired 't' test of control group and stability ball exercise group

\begin{tabular}{|l|l|l|l|l|}
\hline \multicolumn{2}{|c|}{ BMI } & \multicolumn{1}{c|}{ Mean } & \multicolumn{1}{c|}{ S.D } & Significance \\
\hline Control Group & Pre Test & 28.5 & 0.45 & P $>0.000$ \\
\cline { 2 - 4 } & Post Test & 29 & & \\
\hline $\begin{array}{l}\text { Stability Ball Exercise } \\
\text { Group }\end{array}$ & Pre Test & 26.60 & 2.65 & P $<0.05$ \\
\cline { 3 - 4 } & Post Test & 25 & & \\
\hline
\end{tabular}

As displayed in above Table 1, stability ball xercise group subjects have lowered body mass index and 
is statistically significant at $\mathrm{P}<0.05$ and $5 \%$ probability level, hence is effective in the management of Type 2 diabetic patients.

At the same time subjects in control group, where as BMI have an increased BMI and statistically insignificant.

Glycelated Haemoglobin;

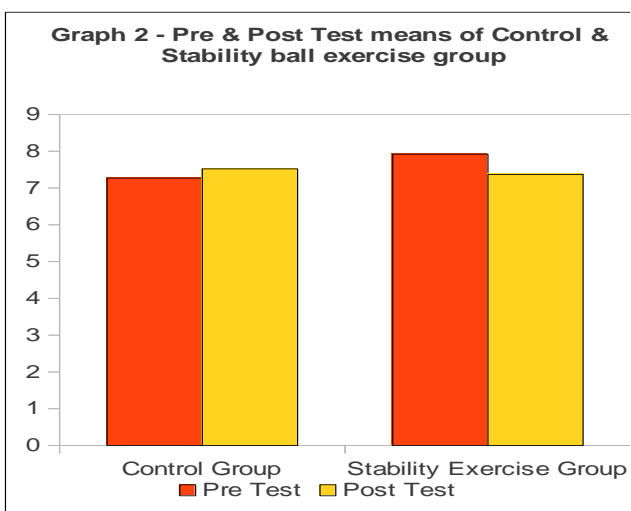

Mean values among stability ball exercise subjects have decreased by $0.55 \%$, where as mean values of control group subjects have increased by $0.25 \%$. As displayed above in Graph 2 .

Table 2; Results of Paired ' $t$ ' test among control group and stability ball exercise group.

\begin{tabular}{|l|l|l|l|l|}
\hline \multicolumn{2}{|c|}{ HbA $_{1}$ C } & \multicolumn{1}{c|}{ Mean } & S.D & Significance \\
\hline Control Group & Pre Test & 7.27 & 0.22 & P $>0.000$ \\
\cline { 3 - 4 } & Post Test & 7.52 & & \\
\hline $\begin{array}{l}\text { Stability Ball Exercise } \\
\text { Group }\end{array}$ & Pre Test & 7.92 & 1.21 & $\mathrm{P}<0.001$ \\
\cline { 3 - 4 } & Post Test & 7.37 & & \\
\hline
\end{tabular}

As shown in Table 2, stability ball exercises are effective in lowering HbA1C, which is evident statistically at $\mathrm{P}<0.001$ and $10 \%$ probability level, where as control group results were statistically insignificant.

\section{Discussion}

This research study confirms that stability ball exercises were effective in lowering Body Mass Index and Glycelated Haemoglobin. Maximal muscle activity of 50\% versus $9 \%$ on activities performed on stability ball and stable bench respectively (Marshall, Murphy et al 2006). Exercises using Stability ball were effective in improving core strength, Endurance and Balance in sedentary women (Sekendez Bet et al 2010).

Insulin absorption is more with exercises to lower extremity than given to upper extremity (Koivitste, Fligp et al 1978). Glycaemic control improves with resistance training involving major muscle groups (Baldi, Sandvling et al 2003). A better glucose control was observed due to improvement in Insulin sensitivity and effects of glucose transporters due to muscular hypertrophy and blood flow (Plong, Raltson et al 2002).

Moderate intensity resistance training results in a mean reduction of Glycelated Haemoglobin by $1 \%$ to $2 \%$ (Dustan, Puddey et al 1998). Among women with Type 2 diabetes a reduction of $0.5 \%$ to $1 \%$ of HbA1C in response to resistance exercises (Cuff, Meneily et al 2003).

$1 \%$ decrement in $\mathrm{HbA1C}$ can reduce the risk of diabetic complications such as myocardial infarction and microvascular disease (Stratton, Well et al 2006 and Patel, Mcmohan et al 2008).

In this study a reduction of $0.55 \%$ Glycelated Haemoglobin was recorded, hence is effective in reducing cardiovascular complications to a greater extent among diabetic patients.

Obesity is a powerful determinant and a risk factor for developing diabetes (WHO 2004). Increase in Body Mass Index was demonstrated to increased risk to complications in Type 2 diabetic patients among Asians (Dr Ramachandran et al 1995). A higher BMI and Waist circumference were recorded among Indian diabetic patients (Chandalia et al 1999). Moderate weight loss in obese individual is associated with improvements in a number of cardiovascular risk factors including blood pressure (Dr Golstein 1992), significant reduction in BMI by $1 \mathrm{Kg} / \mathrm{m}^{2}$ following diet and physical activity for 6 months (Oldrogd, Unwin et al 2001). In this study BMI has decreased by $1.6 \mathrm{Kg} / \mathrm{m}^{2}$ following stability ball exercise, hence is quite effective in decreasing obesity related complications among diabetic patients is evident.

Hence Stability ball exercises to lower extremit can form a modality in the comprehensive management of Type 2 diabetes mellitus. Also as preventive means among obese children and adults can facilitate in 
preventing and postponing the onset of Type 2 diabetes along with due dietry measures.

\section{Conclusion}

Life style modifications including regulations in diet, regular physical activities, coupled with medical monitoring of individual will enable to develop a healthy, vibrant future India. Stability ball exercises widely used for recreational means, strengthening of core muscles of spine, can be considered for its extensive impact on neurovascular, endocrine system requires further exploring studies ahead.

\section{Bibliography}

[1]. Burden of diabetes 1995-2025; prevalence, numerical estimates and projections. Diabetes care 1998;21;1414-1131

[2]. Fall CH: Non industrialized countries and affluence. Bt Med Bull 2001;60;33-50.

[3]. Joshi SR:Metabolic syndrome - emerging clusters of the Indian phenotype. Journal of association of physicians India; $2003 ; 51 ; 445-446$.

[4]. Ramachandran A, Snehalatha C, Vishwanathan V, Vishwanathan M, Haffner SM;Risk of Non Insulin dependent Diabetes Mellitus conferred by obesity and central adiposity in different ethnic groups; Diabetic reference clinical practice; 1997; $36 ; 121-5$

[5]. Raji A, Seely EW, Arky RA, Simonson DC; Body fat distribution and insulin resistance in healthy Asian Indians and Caucasians. J Clin Endocrinology metab 2001; 86; 5366-71.

[6]. Mohan V, Deepa M, Deepa R, Shanthi rani CS, Farooq S, Ganesan A et al. Scular trends in the prevalence of diabetes and glucose intolerance in urban south india - the chennai urban rural epidemiology study (CURES-17) Diabetologia 2006; 49; $1175-8$.

[7]. Storlein LH, Baur LA, Kriketos AD et al. Dietry fats and Insulin action. Diabetologia 1996; 39;621-31.

[8]. Mohan V, Shanthirani CS, Deepa R.Glucose intolerance in a selected south Indian population with special reference to family history, obesity and life style factors - The (UPS14) Journal association of physicians india 2003; $51 ; 771-777$.

[9]. Ramachandran A, Snehalatha C, Vijay V. Impact of poverty on the prevalence of Diabetes and its complications in urban southern India; Diabetes medicine 2002; 19; $130-135$.

[10]. Knavler WC, Barrett-connor E, Pauler SE, Hamman RF, Laclin JM, Walker EA et al. Diabetes prevention program research group. Reduction in the incidence of Type 2 diabetes with life style intervention. N engl J med 2002; 346; 393-403.

[11]. Ramachandran A, Snehalatha C, Kapur A, Vijay V, Mohan V, Das AK et al. Diabetes epidemiology study group in India (DESI). High prevalence of Diabetes and impaired glucose tolerance in India. National urban Diabetes survey; Diabetologia 2001; 44; $1094-101$.

[12]. Wild S, Roglic G, Green A, Sicree R, King H, "Global Prevalence of diabetes: Estimates for the year 2000 and projections for 2030, diabetes care 2004; Volume- 27, Page: 1047-1053.

[13]. American Diabetes Association; Diabetes mellitus and exercise (Position statement) Diabetes care 2002, 564-568.

[14]. Klans Banm et al, "Efficiency of vibration exercise for glycaemic control in Type 2 diabetes patients", International Journal of Medical sciences, 2007, Volume:4, Issue:3, Page: 159-163.

[15]. Koiviste VA, Fligp, "Effects of leg exercise on insulin", England Journal of medicine, Jan-12-1978, Volume: 298, Page: 279-283.

[16]. University of calgary ottowa 2007. Glycaemic control in Type 2 diabetic patients improves with resistance training.

[17]. Baldi JC, Snawling N, 2003. Resistance training improves glycaemic control in obese Type 2 diabetic man. International Journal of sports medicine 24; 419-423.

[18]. Ploug T, Ralston E, "Exploring the whereabouts of GLUT4 in skeletal muscle", Molecular Membrane Biology, 2002, volume:19, Page: 39-49.

[19]. Dustan DW, Puddey, Burkey V. 1998, Effects of a short term circuit weight training programme in non-insulin dependent diabetes mellitus; Diabetes research and clinical practice 40, 53-61.

[20]. Advance Colloborative group; Patel A, Macmohan S, Chalmers J, Neal B, Billot L et al 2008. Intensive blood glucose control and vascular outcomes in patients with Type 2 diabetes, Northern england journal of medicine; 358; 24; $2560-2572$.

[21]. IM Stratton, CA Cull, AI Adler, DR Mathews, HAW Neil, RR Holman, "Additive effects of glycaemia and blood pressure exposure on risk of complications in type 2 diabetes, diabetologia, 2006, Volume:49, Page: 1761-1769.

[22]. Marshal PW, BA Murphy. Increased deltoid and abdominal muscle activity during stability ball bench press. J strength conditioning res 20(4); 745-750. 2006.

[23]. National strength and conditioning association 2010, Sekendiz, Betul, Mutlu, Kakkusuz, Feza on effects of Swiss ball core strength training on strength. Endurance, flexibility and balance in sedentary women. J strength cond res 24(11) - 3032-3040, 2010. Studied on core strength training on trunk extensor, flexor, lower limb extensor and flexor.

[24]. WHO 2004 Technical report No: 920 on ways to promote health.

[25]. Dr A Ramachandran et al, "BMI \& Waist Circumference in Type 2 diabetes", International journal of diabetes, 1995, Volume:15.

[26]. Chandalia M, Abate N, Gary A et al. Relationship between generalizes and upper body obesity to insulin resistance in asian Indian men. Journal of clinical endocrinal metabolism; 1999; 84; $2329-35$.

[27]. DJ Golstein. Beneficial effects of modest weight loss, Int J obes related met disorder 16(1992) 397-415.

[28]. Randomised controlled trial evaluating the effectiveness of behavioural interventions to modify cardiovascular risk factors in men and women with impaired glucose tolerance. JC oldrayd, NC Unwin, M White, K Imrie, JC nathus. Diabetes research and clinical practice 52 (2001) 29-43. 